\title{
Fifty years of Harper-Dorn creep: a viable creep mechanism or a Californian artifact?
}

\author{
Praveen Kumar · Michael E. Kassner • \\ Terence G. Langdon
}

Received: 15 May 2006/ Accepted: 10 August 2006/Published online: 4 January 2007

(C) Springer Science+Business Media, LLC 2006

\begin{abstract}
Fifty years ago, in a series of classic creep experiments conducted at the University of California in Berkeley, Harper and Dorn obtained unique experimental data revealing the possibility of a new and heretofore unrecognized flow process occurring in pure aluminum when tested at low stresses and at temperatures very close to the melting temperature. This flow mechanism, subsequently designated Harper-Dorn creep, has been the center of much argument and speculation in the ensuing years. The present paper looks back over the last half-century and charts the various developments in attempts to obtain a more detailed understanding of whether Harper-Dorn creep is (or is not) a viable creep process. Examples are presented for both metals and non-metals. It is concluded that, although it appears Harper-Dorn creep may occur only under restricted conditions associated with high purity materials and low initial dislocation densities, nevertheless there is good evidence supporting the validity of this creep mechanism as a viable and unique flow process.
\end{abstract}

"There is science, logic, reason; there is thought verified by experience. And then there is California...."

Edward Abbey (1927-1989)

American author, essayist and environmentalist

P. Kumar · M. E. Kassner · T. G. Langdon ( $\square)$

Departments of Aerospace \& Mechanical Engineering and Materials Science, University of Southern California, Los Angeles, CA 90089-1453, USA

e-mail: langdon@usc.edu

\section{Introduction}

When a stress is applied to a polycrystalline solid, the material breaks if the stress is sufficiently high but when the stress is low the material gradually deforms plastically over a period of time leading ultimately to failure. This extensive deformation with time is known as creep and it occurs more readily at high temperatures when diffusion-controlled processes are reasonably rapid. In practice, the rate of creep in any crystalline solid is dependent upon the testing temperature, the magnitude of the applied stress and the microstructural characteristics of the material. Generally, the variation of strain with time exhibits three distinct regions: there is an initial or primary region where the rate of strain decreases with increasing strain, there is often an extended secondary or steadystate region where the strain rate remains essentially constant and there is a third or tertiary region where the strain rate accelerates to final fracture. Many of the theoretical creep mechanisms developed to date are concerned with predicting the rate of flow within the secondary or steady-state region.

When polycrystalline metals deform under steadystate conditions, it is well established that the creep rate, $\dot{\varepsilon}$, varies with the applied stress, $\sigma$, the absolute testing temperature, $T$, and the grain size, $d$, through a relationship of the form

$\dot{\varepsilon}=A\left(\frac{D G \mathrm{~b}}{k T}\right)\left(\frac{\mathrm{b}}{d}\right)^{p}\left(\frac{\sigma}{G}\right)^{n}$

where $D$ is the appropriate diffusion coefficient, $G$ is the shear modulus, $\mathbf{b}$ is the Burgers vector, $k$ is Boltzmann's constant, $n$ and $p$ are the stress exponent 
and the exponent of the inverse grain size, respectively, and $A$ is a dimensionless constant.

For polycrystalline materials tested under creep conditions over a wide range of intermediate stresses, the steady-state creep rate usually varies with the applied stress raised to a power lying typically within the range of $\sim 3-5$ and the behavior is interpreted in terms of dislocation flow processes occurring within the grains. In practice, essentially similar power-law creep is observed in a very wide range of crystalline materials including metals $[1,2]$, ceramics [3, 4], geological minerals [5] and ice [6]. At very high stresses the creep rate usually increases rapidly with stress in the region of power-law breakdown whereas at very low stresses there is another transition to a region where the stress exponent is very low and typically close to 1 . This paper is concerned specifically with the flow characteristics in this low stress region where the behavior approximates to Newtonian viscous flow with a stress exponent of $n \approx 1$. To place this report in perspective, the following section examines the potential flow mechanisms occurring at low stresses, the next section presents some of the arguments for and against the advent of Harper-Dorn creep as a separate flow process and the subsequent sections provide a comprehensive appraisal of the reported creep behavior occurring in this low stress region.

\section{Potential creep mechanisms at low stresses when $n=1$}

The traditional view of creep has always argued that the flow behavior at very low stresses occurs through some form of diffusion creep wherein flow takes place not because of a dislocation mechanism but rather because of the stress-directed diffusion of vacancies. The principle of diffusion creep was first proposed by Nabarro [7] and subsequently the mechanism was developed in a mathematical form by Herring [8]. This process, now known as Nabarro-Herring diffusion creep, predicts a creep rate of the form shown in Eq 1 with $n=1, p=2$ and $D=D_{\ell}$, where $D_{\ell}$ is the coefficient for lattice self-diffusion. At a later date, Coble [9] noted that vacancies may also diffuse along the grain boundaries and this leads to the process now known as Coble diffusion creep where $n=1, p=3$ and $D=D_{\mathrm{gb}}$, where $D_{\mathrm{gb}}$ is the coefficient for grain boundary diffusion.

A very important development occurred exactly fifty years ago in 1957 when Harper and Dorn [10], working at the University of California (UC), Berkeley, obtained results suggesting the advent of a new and possibly significantly different flow mechanism within the low-stress region of Newtonian viscosity. By performing creep tests on high purity $(99.99 \%)$ aluminum with large grain sizes $(-3.3 \mathrm{~mm})$ and using testing temperatures very close to the absolute melting temperature $(920 \mathrm{~K}$ corresponding to an homologous temperature of $\sim 0.99 T_{\mathrm{m}}$, where $T_{\mathrm{m}}$ is the absolute melting temperature), these investigators documented steady-state creep rates which increased linearly with the applied stress so that $n=1$. They found also that the activation energy for creep was equal to the anticipated value for lattice self-diffusion so that $D=D_{\ell}$ but the experimental creep rates were a factor of $\sim 1400$ greater than the theoretical predictions for Nabarro-Herring creep. In addition, Harper and Dorn [10] tested an aluminum single crystal and obtained a similar creep rate despite the fact that diffusion creep is a mechanism that occurs only in polycrystalline materials. This unusual behavior was subsequently termed Harper-Dorn creep [1] and, over the last fifty years, it has become a topic of considerable debate and contention.

The results of Harper and Dorn [10] are shown in Fig. 1 where the steady-state creep rate is plotted logarithmically against the applied stress, the open

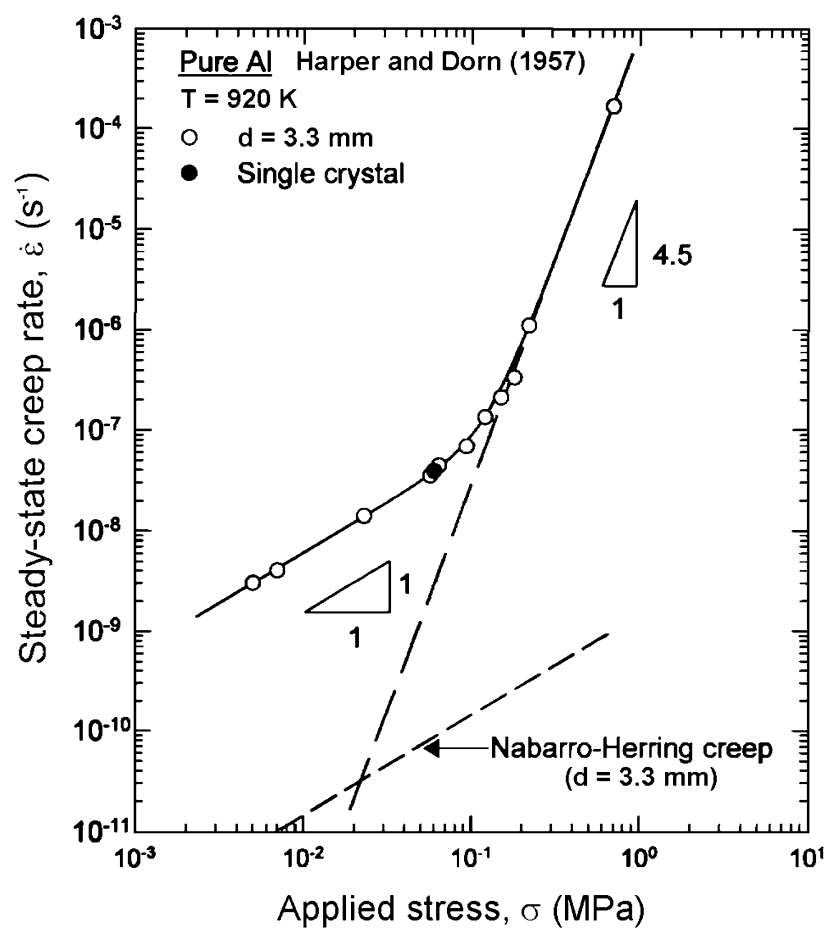

Fig. 1 Steady-state creep rate versus applied stress from the results of Harper and Dorn [10] for pure aluminum tested at a temperature of $923 \mathrm{~K}$ : the lower broken line shows the prediction for Nabarro-Herring diffusion creep for a grain size of $3.3 \mathrm{~mm}$ 
points show data from the polycrystalline specimens, the solid point denotes the creep rate measured in the single crystal and the lower broken line denotes the predicted creep rate for Nabarro-Herring creep with a grain size of $3.3 \mathrm{~mm}$. It should be noted that the values of the applied stress plotted in Fig. 1 strictly represent the levels of the effective stress because Harper and Dorn [10] measured and deducted a very small threshold stress which was attributed to the effects of surface tension. The plot in Fig. 1 shows a transition with decreasing stress from power-law creep with $n \approx 4.5$ at the higher stress levels to a well-defined region with $n=1$ at low stresses. The region with $n \approx 4.5$ is similar to a very wide range of creep data reported for pure aluminum [1] and clearly the experimental data in the low stress region are mutually consistent although they deviate by more than three orders of magnitude from the theoretical prediction for diffusion creep. This deviation far exceeds any possible errors inherent in the experiments, especially when it is noted that the steady-state strain rates measured in low stress creep experiments, at least for pure metals, are generally consistent with, or at least very close to, the predictions of the theoretical Nabarro-Herring mechanism [11]. It is reasonable to conclude, therefore, that the flow behavior in the experiments of Harper and Dorn [10] probably occurred by an unidentified intragranular dislocation mechanism. Further support for the results of Harper and Dorn [10] was published in 1958 in a report providing additional information on the characteristics of flow in this low stress region [12].

Since Harper-Dorn creep is concerned with the flow process occurring when a material is subjected to a very low level of the applied stress, it follows that the measured strain rates are extremely low. In Fig. 1, for example, the Harper-Dorn regime corresponds to creep rates in the range from $10^{-9}$ to $10^{-7} \mathrm{~s}^{-1}$. Despite these potentially very slow rates, the possible occurrence of Harper-Dorn creep is of considerable current interest both in terms of long-term industrial applications where components are subjected to low loads for extended periods of time and in geological materials where, typically, the flow strain rates are of the order of $\sim 10^{-16}-10^{-14} \mathrm{~s}^{-1}$. There are many examples where metallic components used in structural applications are subjected to relatively low stresses over exceptionally long periods of time. An example is the nuclear industry where structural design limits are often based on periods of time of the order of $2 \times 10^{5} \mathrm{~h}$ ( $>20$ years) so that there is an important requirement for nuclear engineers, especially in view of safety considerations, to obtain information on the precise flow behavior occurring during creep at very low stresses. In the field of earth sciences, there are several suggestions that Harper-Dorn creep may be important in the flow of planetary and lunar interiors [13-15] and there appears to be direct laboratory evidence for the occurrence of Harper-Dorn creep in two silicate perovskite analogues, $\mathrm{KZnF}_{3}$ [16] and $\mathrm{KTaO}_{3}$ [17]. These latter results are especially significant when it is noted that the major constituent within the lower mantle of the Earth is $(\mathrm{Mg}, \mathrm{Fe}) \mathrm{SiO}_{3}$.

\section{Arguments for and against the advent of Harper-Dorn creep as a viable flow process}

There have been numerous attempts over the last fifty years either to essentially duplicate the early experiments of Harper and Dorn [10] by conducting creep tests on aluminum at low stresses or by extending the experimental evidence for Harper-Dorn creep by testing other materials in the low stress regime. At the same time, evidence has been put forward both strongly refuting and strongly supporting the concept of Harper-Dorn creep as a separate and viable creep mechanism. Thus, Weertman and Blacic [18] published a paper titled "Harper-Dorn Creep: An Artifact of Low-Amplitude Temperature Cycling" in which they argued the results purporting to support Harper-Dorn creep may be produced inadvertently by low-amplitude temperature cycling during long-term testing at very high temperatures. They suggested that erroneous trends may be recorded even with a long-term temperature cycling of only $\pm 1 \mathrm{~K}$ but this proposal received little support because it seems unlikely that any long-term cycles will occur with sufficient regularity to give the consistency in datum points shown within the $n=1$ region in Fig. 1 .

Subsequently, Blum and Maier [19] published a paper titled "Harper-Dorn Creep-a Myth?" in which, based on their own experimental observations on pure polycrystalline aluminum tested in compression at $923 \mathrm{~K}$, they argued against the concept of Harper-Dorn creep because they failed to find a transition to a region of $n \approx 1$ at their lowest stresses. However, these results can be neglected because a critical review of the work shows that the compression tests were conducted using nominally cubic specimens with an aspect ratio of "about one" and it is well known that higher aspect ratios (at least $>1.5$ ) are a necessary prerequisite for measuring the true strain rates in compression testing because of the occurrence of a region of restricted slip at either end of the compression samples [20]. Furthermore, the arguments in favor of Harper-Dorn creep were later put forward 
in a spirited defense by Nabarro [21] entitled "HarperDorn Creep-A Legend Attenuated?" where it was noted that the determinations of the stress exponent by stress change testing in the experiments of Blum and Maier [19] "were made at stresses above those at which Harper-Dorn creep is known to give way to power-law creep."

By contrast to the debate on the relative merits of Harper-Dorn creep, Ruano et al. [22] developed an alternative approach in a paper titled "Evidence for Nabarro-Herring Creep in Metals: Fiction or Reality?" in which they argued against "all creep data in metals ascribed to the Nabarro-Herring diffusional creep mechanism" and they proposed instead that these data may be satisfactorily interpreted in terms of the occurrence of grain boundary sliding and HarperDorn creep.

These various conflicting reports demonstrate the uncertainties inherent in interpreting the creep data obtained at these very low stress levels and accordingly it is necessary to re-evaluate the published data, obtained subsequent to the early work of Harper and Dorn [10], which appears to either support or negate the advent of a separate Harper-Dorn creep mechanism.

\section{Experimental evidence on metals in the regime anticipated for Harper-Dorn creep}

Several reports are now available documenting the creep behavior of materials, primarily pure aluminum, tested under conditions where it is reasonable to anticipate the occurrence of Harper-Dorn creep. It is worthwhile examining these various reports in chronological order.

Shortly after the work of Harper and Dorn [10], Barrett et al. [23] at Stanford University, California, confirmed the Harper-Dorn data using polycrystalline pure $\mathrm{Al}$, they demonstrated that similar strain rates were recorded with $\mathrm{Al}$ single crystals, they reported a stress exponent of $n=1$ and they showed the measured creep rates were more than three orders of magnitude faster than the rates predicted for Nabarro-Herring diffusion creep. On the other hand, Muehleisen et al. [24], also at Stanford, were unable to reproduce Harper-Dorn creep in compression tests on $\mathrm{Cu}$ and Burton [25] in the U.K. failed to observe Harper-Dorn creep in large-grained $\mathrm{Al}$ specimens of $99.99 \%$ purity when testing near the absolute melting temperature. These variations in behavior suggest there are some additional features associated with the advent of true Harper-Dorn creep.
There are reports of good agreement with the data of Harper and Dorn [10] in a series of experiments conducted at UC Berkeley by Murty et al. [26] using $\mathrm{Al}-3 \% \mathrm{Mg}$, by Mohamed et al. [27] using high purity $\mathrm{Al}, \mathrm{Pb}$ and $\mathrm{Sn}$, and later by Murty [28] with a Pb-9\% Sn alloy and Mohamed [29] with an $\mathrm{Al}-2 \% \mathrm{Mg}$ alloy. Harper-Dorn creep was also confirmed in experiments conducted at the University of Southern California on polycrystalline $\mathrm{Al}-3 \% \mathrm{Mg}[30,31]$.

Although the preceding sets of experiments refer to simple confirmations of the Harper-Dorn flow mechanism, Mohamed and Ginter [32] of the University of California, Irvine, made an important contribution in 1982 by evaluating the potential for achieving HarperDorn creep in samples of aluminum prepared using different processing procedures. From these experiments, it was shown that Harper-Dorn creep is achieved only when the internal dislocation density prior to testing is exceptionally low (for example, $10^{7}-3 \times 10^{8} \mathrm{~m}^{-2}$ in annealed samples). By contrast, Harper-Dorn creep was not observed, either in polycrystalline $\mathrm{Al}$ or single crystal $\mathrm{Al}$, when the initial dislocation density was of the order of $10^{10} \mathrm{~m}^{-2}$. This result is important because it shows there are clearly defined experimental requirements for attaining Harper-Dorn creep and this creep process will be absent if these requirements are not fulfilled. It should be noted that this result is consistent with earlier reports of initial dislocation densities in materials exhibiting Harper-Dorn creep of $3 \times 10^{8} \mathrm{~m}^{-2}$ [27] and $1 \times 10^{7} \mathrm{~m}^{-2}$ [23]. There is also indirect evidence from these experiments that purity may play a role because Harper-Dorn creep was not observed in samples of 99.99\% purity with a high dislocation density but Harper-Dorn flow was revealed in very high purity 99.9995\% Al with a low initial dislocation density of $\sim 10^{8} \mathrm{~m}^{-2}$. However, the evidence for a purity effect tends to be negated by the subsequent work of Lee and Ardell [33], conducted at the University of California, Los Angeles, where excellent agreement was obtained with the behavior anticipated for Harper-Dorn creep in experiments conducted on single crystals of $\mathrm{Al}$ of 99.99\% purity with the crystals tested in compression using parallelepiped samples with an acceptable aspect ratio of 2. As already noted, the later work of Blum and Maier [19] in Germany, where Harper-Dorn creep was not observed in $99.99 \%$ purity $\mathrm{Al}$ single crystals, is inconclusive because the tests were conducted on compression samples using an unacceptably low aspect ratio of $\sim 1$ where it is reasonable to anticipate, as indeed reported, that the measured strain rates will be exceptionally low by comparison with the rates anticipated for the Harper-Dorn process. 
In an attempt to resolve these various conflicting results, a detailed and comprehensive evaluation of the occurrence of Harper-Dorn creep was conducted by Ginter et al. [34] at UC Irvine. These experiments confirmed that Harper-Dorn creep was attained in $\mathrm{Al}$ of $99.9995 \%$ purity but not in $\mathrm{Al}$ of $99.99 \%$ purity and, in addition, the creep curves obtained in the very high purity material exhibited regular and periodic accelerations which were attributed to the occurrence of dynamic recrystallization [35]. By contrast, it was shown conclusively that specimens with high initial dislocation densities $\left(\sim 10^{10} \mathrm{~m}^{-2}\right)$ and low purity $(99.99 \%)$ do not exhibit Harper-Dorn creep and instead the behavior is dominated by dynamic recovery. An important additional observation was that the creep behavior no longer follows a stress exponent of $n=1$ when the tests are extended to very high strains of $>0.1$ but instead there is evidence for a stress exponent of $n>2$.

Very recently, tensile creep experiments were performed by McNee et al. [36] in the U.K. using polycrystalline aluminum with three different purities: 99.99, 99.998 and $99.999 \%$. The results from these experiments, which were conducted very close to the melting temperature, gave creep rates for all purities which were significantly lower than those anticipated for Harper-Dorn creep. In later work by the same group, Srivastava et al. [37] tested OFHC Cu in tension at temperatures close to the melting temperature and obtained creep rates that were approximately two orders of magnitude faster than the rates predicted for Nabarro-Herring diffusion creep. These very rapid rates are similar to earlier creep data reported for $\mathrm{Cu}$ by Pines and Sirenko [38] which were subsequently interpreted by Mohamed [39] as possibly indicative of the occurrence of Harper-Dorn creep. Furthermore, the rates are consistent with those anticipated for Harper-Dorn creep although the measured stress exponent was closer to $n \approx 2$ rather than $n=1$. However, this latter result is consistent both with the recent results of Ginter et al. [34] on aluminum tested to strains of $>0.1$ and with results obtained from experiments currently in progress on specimens of $\mathrm{Pb}$ of $99.999 \%$ purity [40].

Although all of the preceding reports relate to experimental conditions in which the testing temperatures were extremely high, typically above $\sim 0.95 T_{\mathrm{m}}$ as in the original experiments of Harper and Dorn [10], there are also several additional reports describing the advent of a similar flow mechanism with $n \approx 1$ in experiments conducted at much lower temperatures, in the vicinity of $\sim 0.5 T_{\mathrm{m}}$, using specimens constructed in the form of helical coils. These various reports have been interpreted in terms of the occurrence of a lowtemperature type of Harper-Dorn creep with reports available to date for experiments on Co [41, 42], Ti [41, 43], Fe [44-46], Zr [47-49], a Ni-Cr alloy [50] and pure $\mathrm{Al}$ [51]. However, since these results relate to homologous temperatures which are far removed from the original report by Harper and Dorn [10], these data are not considered in this brief overview.

\section{Evidence for the occurrence of Harper-Dorn creep in ceramic and geological materials}

As already noted, there are experimental data supporting the occurrence of Harper-Dorn creep in two geological materials, $\mathrm{KZnF}_{3}$ [16] and $\mathrm{KTaO}_{3}$ [17]. There are also experimental results on olivine suggesting the possibility of Harper-Dorn creep at the lowest stress levels [52, 53]. Furthermore, there is good evidence for Harper-Dorn creep in laboratory experiments on $\mathrm{NaCl}$ single crystals where the tests were conducted in compression using samples with an aspect ratio close to $\sim 2$ [54].

Nevertheless, most of the reports suggesting the possibility of the occurrence of Harper-Dorn creep in non-metallic materials are based on re-interpretations of published data. Thus, the early creep data obtained from compression testing of polycrystalline and single crystal $\mathrm{CaO}$, using compression samples with an aspect ratio of 1.5 [55], were subsequently interpreted as indicative of Harper-Dorn creep because the results were generally in agreement with this mechanism including a similarity in creep rates for the single crystal and polycrystalline samples [56]. Several reports are now available suggesting that Harper-Dorn creep may occur in a wide range of ceramic and geological materials [57-63]. However, these reports must be approached with caution because subsequent inspection has shown that at least some of the proposals are probably erroneous because the available data do not fulfill the requirements for unambiguously establishing the advent of the Harper-Dorn flow mechanism $[64,65]$.

Since Harper-Dorn creep may be an important flow mechanism in lunar and planetary interiors, it is appropriate to examine in detail the creep data available for a selected range of ceramic and geological materials. Making use of Eq. 1, Figs. 2-5 show experimental creep data plotted logarithmically in the form of the normalized strain rate, $\dot{\varepsilon} k T / D G$ b, versus the normalized stress, $\sigma / G$, for $\mathrm{CaO}, \mathrm{LiF}, \mathrm{MgO}$ and $\mathrm{NaCl}$, respectively. Similar plots are shown in Fig. 6 and 7 for dry olivine $\left(\left(\mathrm{Mg}_{4} \mathrm{Fe}\right) 2 \mathrm{SiO}_{2}\right)$ and forsterite $\left(\mathrm{Mg}_{2} \mathrm{SiO}_{4}\right)$ 


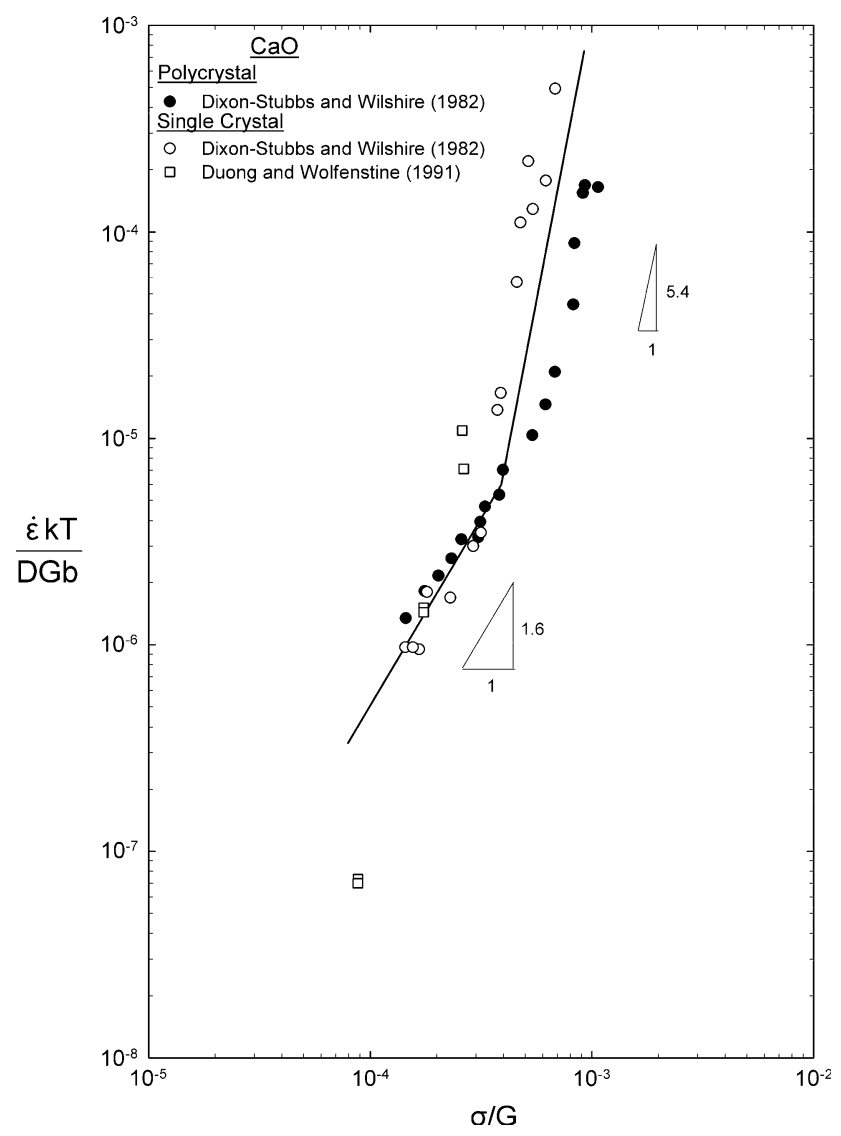

Fig. 2 Normalized creep rate versus normalized stress for polycrystalline [55] and single crystal [66] $\mathrm{CaO}$

and the relevant sources for all of the creep data are summarized in Table 1 for single crystals and in Table 2 for polycrystalline materials.

In constructing these plots, the values used for the diffusion coefficient $D$ and the shear modulus $G$ are summarized in Table 3 . The value of $D$ is expressed as $D_{\mathrm{o}} \exp (-Q / R T)$ where $D_{\mathrm{o}}$ is the frequency factor, $Q$ is the activation energy for diffusion of the active ion and $R$ is the gas constant and the value of the shear modulus of elasticity $G$ is expressed as $\left(G_{o}-\Delta G T\right)$ where $G_{o}$ is the value of the shear modulus extrapolated linearly to absolute zero and $\Delta G$ is the rate of decrease of the shear modulus with increasing temperature. For $\mathrm{CaO}$, there is at present no value available for the diffusion coefficient for the anion. Therefore, the value of $Q \approx 345 \mathrm{~kJ} \mathrm{~mol}^{-1}$ shown in Table 3 was taken from the activation energy for creep measured by Duong and Wolfenstine [66] and the value of $D_{\text {o }}$ $\left(2.0 \times 10^{-10} \mathrm{~m}^{2} \mathrm{~s}^{-1}\right)$ was estimated from the established values of $D_{\mathrm{o}}$ for $\mathrm{MgO}\left(2.5 \times 10^{-10} \mathrm{~m}^{2} \mathrm{~s}^{-1}\right)$ and $\mathrm{NiO}$ $\left(1 \times 10^{-9} \mathrm{~m}^{2} \mathrm{~s}^{-1}\right)$. Similarly, no values are available for $D$ and $G$ in forsterite but olivine contains $90-92 \%$ of forsterite and, since the $\mathrm{Si}$ ion is the slower moving

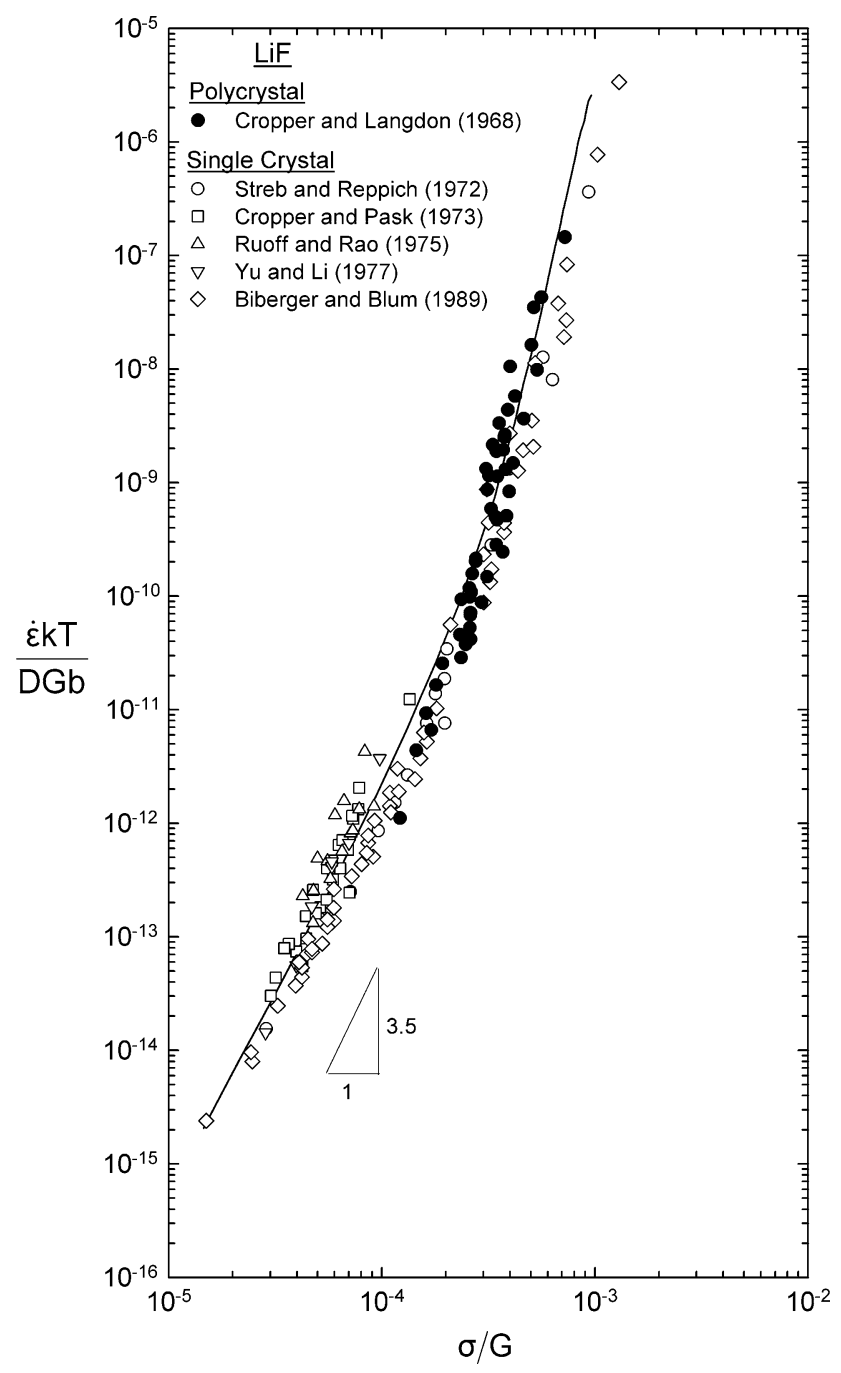

Fig. 3 Normalized creep rate versus normalized stress for polycrystalline [67] and single crystal [68-72] $\mathrm{LiF}$

species in both forsterite and olivine, it is reasonable to perform the normalization of creep data using the same values of $D$ and $G$ for both materials. It should be noted that in practice the diffusion of Si appears to be $\sim 30$ times faster in olivine than forsterite within the temperature range of $1130-1530{ }^{\circ} \mathrm{C}$ [93] but nevertheless this only introduces a factor which has no influence on the normalization and the subsequent relative agreements between the various sets of datum points shown in Fig. 7. An important additional point is that forsterite has an ortho-rhombic structure and the notation given in Fig. 7 for forsterite single crystals denotes the loading direction with respect to the largest lattice parameter, $c$.

Inspection of Figs. 2-7 reveals several significant trends. First, the datum points for $\mathrm{CaO}$ in Fig. 2 are reasonably normalized despite the necessity of 


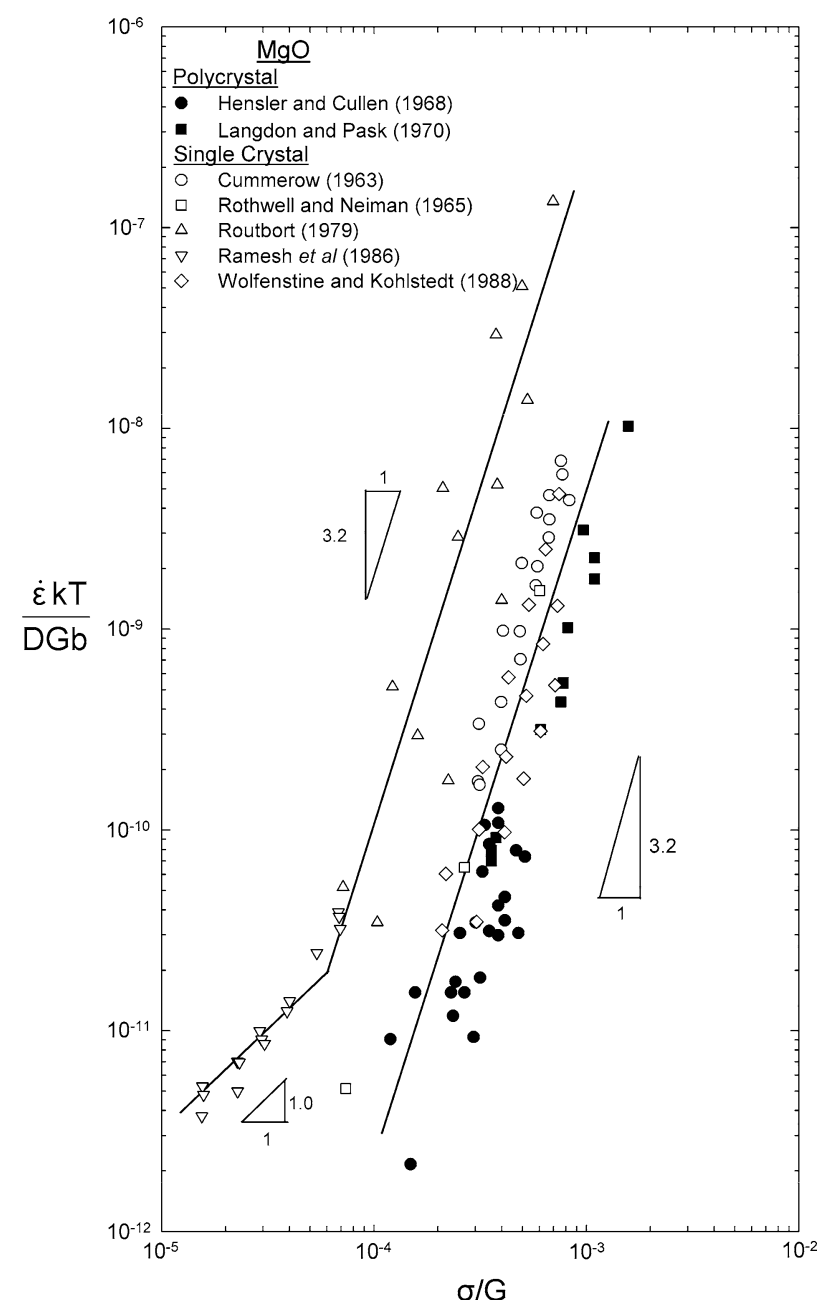

Fig. 4 Normalized creep rate versus normalized stress for polycrystalline $[73,74]$ and single crystal [75-79] $\mathrm{MgO}$

estimating an appropriate value for $D$ based on the measured activation energy in creep testing. The plot in Fig. 2 shows a transition to a region of lower slope at the lowest stress levels and similar transitions are visible also in the data for $\mathrm{MgO}$ and $\mathrm{NaCl}$ in Figs. 4 and 5. Surprisingly, there is no equivalent transition in the data for $\mathrm{LiF}$ despite the very large number of individual datum points extending over a range of nine orders of magnitude in the normalized strain rate. In fact, the experimental results for $\mathrm{LiF}$ are in remarkably good agreement although results are plotted from six independent investigations [67-72]. Furthermore, the results for $\mathrm{LiF}$ extend to an exceptionally low normalized strain rate of $\dot{\varepsilon} k T / D G \mathrm{~b} \approx 3 \times 10^{-15}$. For $\mathrm{NaCl}$ shown in Fig. 5, the results of Banerdt and Sammis [54] at the lowest stresses have been interpreted as direct evidence for Harper-Dorn creep. There is also similar evidence for dry olivine and forsterite with stress exponents very close to 1 at the lowest stresses.

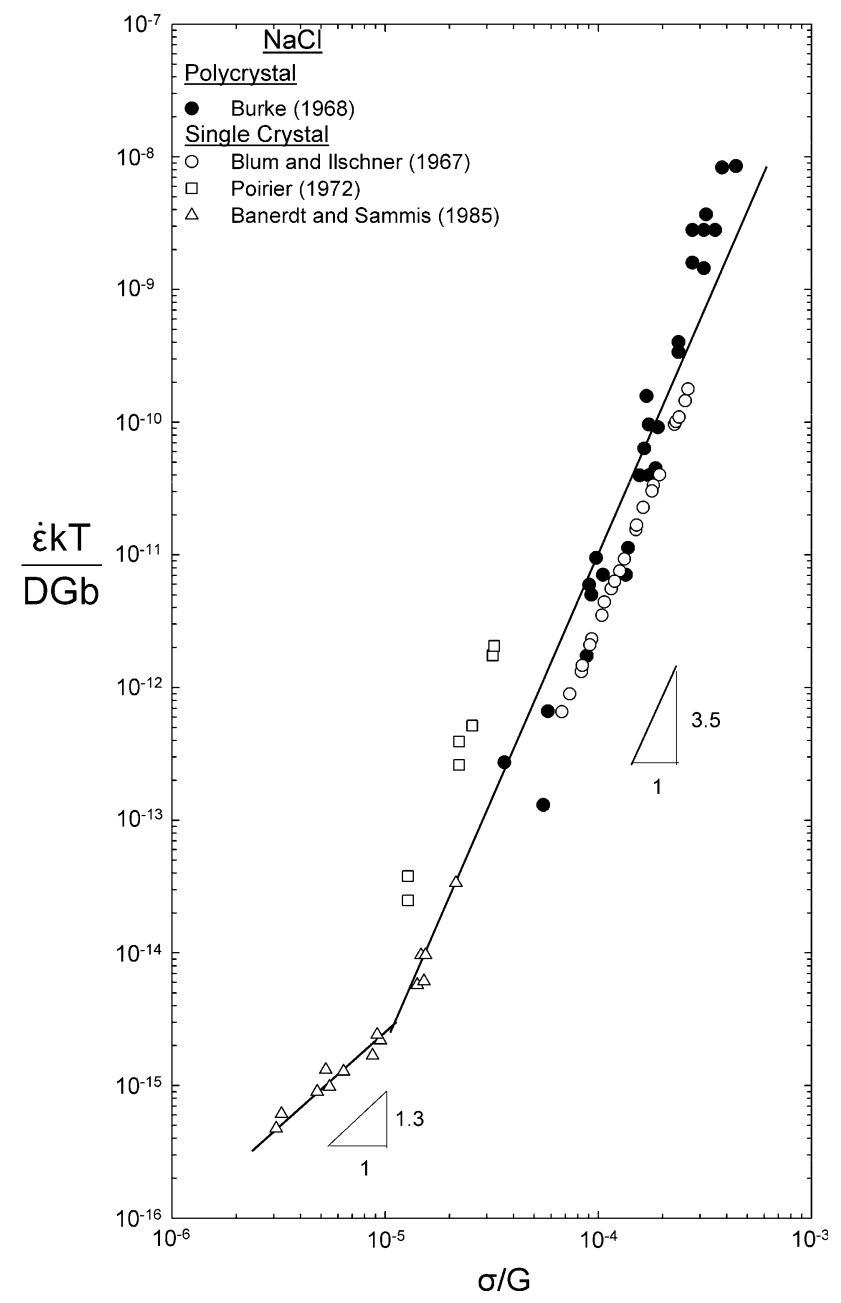

Fig. 5 Normalized creep rate versus normalized stress for polycrystalline [80] and single crystal $[54,81,82] \mathrm{NaCl}$

Two points should be noted in reviewing these plots. First, the data for $\mathrm{MgO}$ appear to divide into two separate sections within the power-law region with both regions have a stress exponent of $n \approx 3.2$. The reason for this division is not known but it may reflect differences in impurity levels in the different batches of single crystals. Second, there is a clear division in Fig. 7 within the power-law region for forsterite but this is simply a reflection of the different orientations of [110], [101] and [011] used for the single crystals and the consequent inability to meaningfully incorporate these differences into the normalization procedure.

In summary, with the exception only of $\mathrm{LiF}$, all of these materials show evidence for a transition to a creep regime having a low value of $n$ at the lowest stresses. Furthermore, where the data for polycrystalline specimens and single crystals are in reasonable agreement at the lowest stresses, as in $\mathrm{CaO}$ in Fig. 2 and olivine in Fig. 6, the evidence is strong that the 


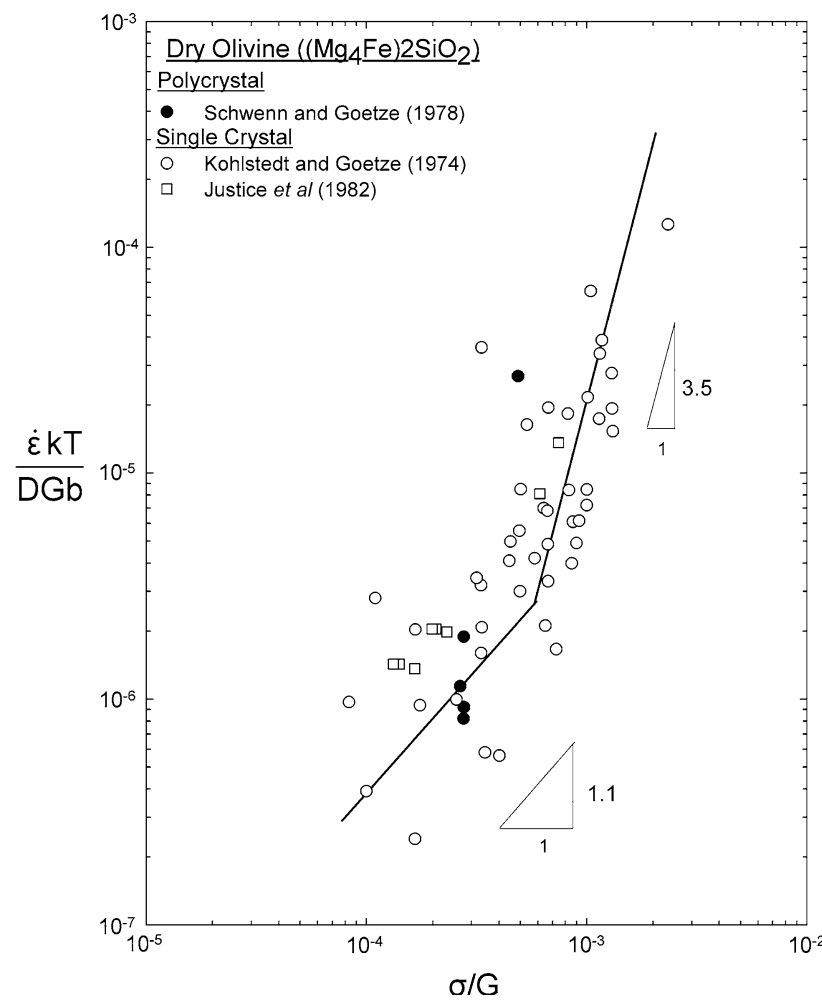

Fig. 6 Normalized creep rate versus normalized stress for polycrystalline [83] and single crystal [52, 53] dry olivine $\left(\left(\mathrm{Mg}_{4} \mathrm{Fe}\right) 2 \mathrm{SiO}_{2}\right.$

creep behavior is not associated with Nabarro-Herring diffusion creep and may instead represent the occurrence of the Harper-Dorn creep mechanism.

\section{General overview of the significance of Harper-Dorn creep}

This report demonstrates that sufficient data are now available to reach definitive conclusions on the possible advent of Harper-Dorn creep. Following the early demonstration, exactly fifty years ago, of a new and distinct flow mechanism at very low stresses when testing pure aluminum at extremely high homologous temperatures [10], it is now apparent that several subsequent reports are available supporting these data but there are also additional requirements, heretofore generally unrecognized, that must be fulfilled in order to reveal the Harper-Dorn regime. These requirements include a low initial dislocation density [32] and the use of materials having a very high purity [34]. For ceramics and geological materials, much of the evidence for Harper-Dorn creep is indirect and lies in the transitions to $n \approx 1$ which are visible in several of these materials at the lowest stress levels. For metals, the experimental evidence is generally more direct and

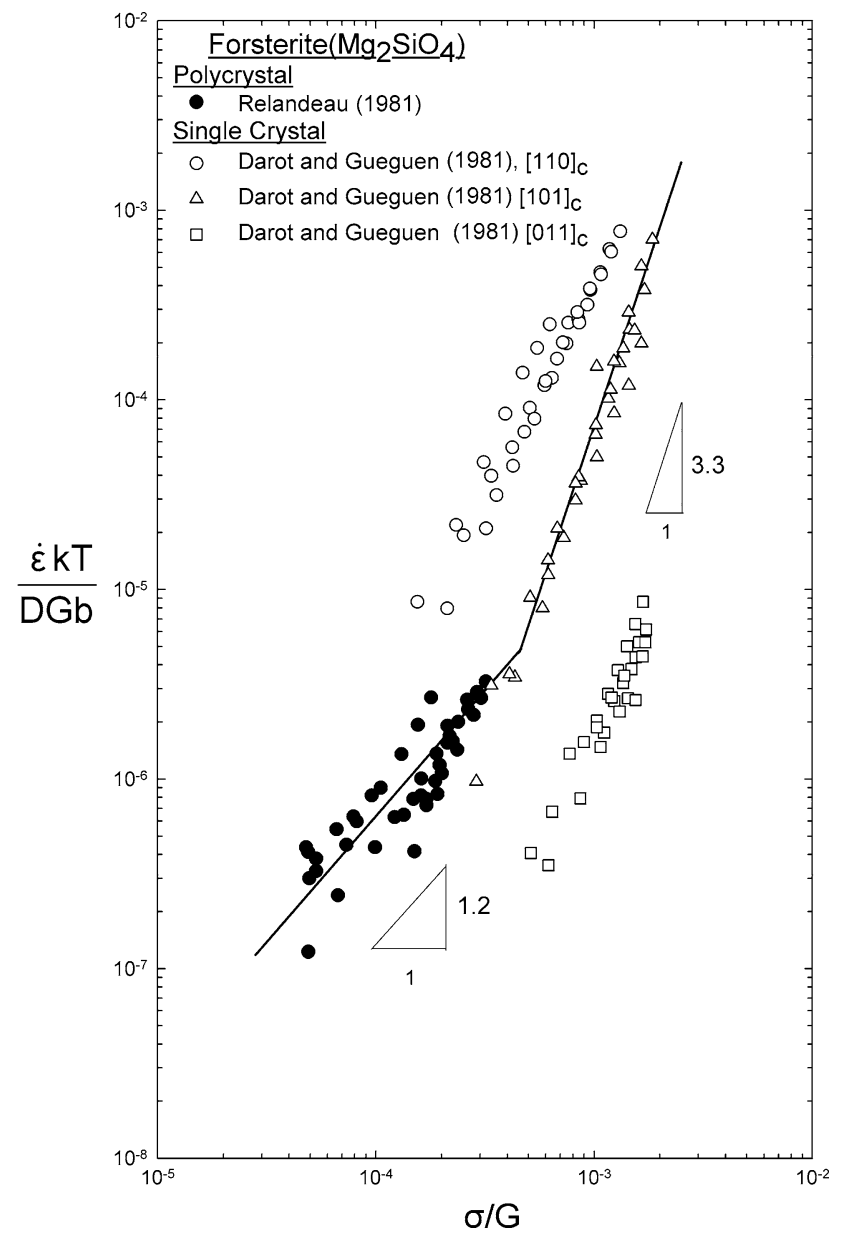

Fig. 7 Normalized creep rate versus normalized stress for polycrystalline [84] and single crystal [85] forsterite $\left(\mathrm{Mg}_{2} \mathrm{SiO}_{4}\right)$

invariably the evidence has been accrued through careful creep testing in the laboratory.

However, despite the general agreement on the occurrence of Harper-Dorn creep between several independent sets of investigators, it is instructive to note that the Harper-Dorn creep mechanism first became manifest in creep experiments conducted in California and the additional evidence accumulated for this phenomenon over the past 50 years is based almost exclusively on various creep experiments performed in California. This may suggest, at least to the uninitiated, that Harper-Dorn creep is little more than a Californian artifact. Accordingly, and in order to allay this proposal and to encourage appropriate experiments in creep laboratories around the world, it is worthwhile setting out the specific requirements that must be fulfilled in order to unambiguously demonstrate the occurrence of the Harper-Dorn creep mechanism.

As already noted, investigations of Harper-Dorn creep in metals require the use of a material with a 
Table 1 Creep of single crystals

\begin{tabular}{|c|c|c|c|c|c|}
\hline Material & Temperature(K) & $\begin{array}{l}\text { Homologous } \\
\text { Temperature }\end{array}$ & Orientation & Purity/Impurity & Reference \\
\hline \multirow[t]{2}{*}{$\mathrm{CaO}$} & 1473 & 0.52 & $\langle 111\rangle,\langle 100\rangle$ & $\begin{array}{l}\text { 99.997\% } \mathrm{CaO}, 1 \mathrm{ppm} \mathrm{Fe}, 2 \mathrm{ppm} \mathrm{Si}, 1 \mathrm{ppm} \\
\mathrm{Na}, 10 \mathrm{ppm} \mathrm{Mg} \text { and } 300 \mathrm{ppm} \mathrm{Sr}\end{array}$ & $\begin{array}{l}\text { Dixon-Stubbs } \\
\text { and Wilshire } \\
\text { [55] }\end{array}$ \\
\hline & 1623 and 1673 & 0.57 and 0.58 & $\langle 100\rangle$ & $\begin{array}{l}99.997 \% \mathrm{CaO}, 80 \mathrm{ppm} \mathrm{Fe}, 80 \mathrm{ppm} \mathrm{Al} \text {, } \\
60 \text { ppm Si }\end{array}$ & $\begin{array}{l}\text { Duong and } \\
\text { Wolfenstine } \\
{[66]}\end{array}$ \\
\hline \multirow[t]{5}{*}{$\mathrm{LiF}$} & $523-1023$ & $0.47-0.97$ & $\langle 100\rangle$ & Divalent impurity $<0.7 \mathrm{~mol} \mathrm{ppm}$ of $\mathrm{Mg}^{2+}$ & $\begin{array}{l}\text { Streb and } \\
\quad \text { Reppich [68] }\end{array}$ \\
\hline & $923-1023$ & $0.81-0.88$ & $\langle 100\rangle$ & Divalent impurity $<17$ ppm & $\begin{array}{l}\text { Cropper and } \\
\text { Pask [69] }\end{array}$ \\
\hline & $923-1023$ & $0.81-0.90$ & $\langle 100\rangle$ & & $\begin{array}{l}\text { Ruoff and Rao } \\
{[70]}\end{array}$ \\
\hline & 923 & 0.81 & $\langle 100\rangle$ & Divalent impurity $<50 \mathrm{ppm}$ & $\mathrm{Yu}$ and $\mathrm{Li}[71]$ \\
\hline & $673-1113$ & $0.59-0.98$ & $\langle 100\rangle$ & Divalent impurity $<1$ ppm & $\begin{array}{l}\text { Biberger and } \\
\text { Blum [72] }\end{array}$ \\
\hline \multirow[t]{5}{*}{$\mathrm{MgO}$} & 1929-1973 & $0.62-0.63$ & & $\begin{array}{l}\text { Possibly same as Ramesh et al. [78]—using } \\
\text { same supplier }\end{array}$ & Cummerow [75] \\
\hline & 1673 & 0.54 & & $\begin{array}{l}\text { Possibly same as Ramesh et al. [78]—using } \\
\text { same supplier }\end{array}$ & $\begin{array}{l}\text { Rothwell and } \\
\text { Neiman [76] }\end{array}$ \\
\hline & $1678-2073$ & $0.54-0.66$ & $\langle 100\rangle$ & $\begin{array}{l}\text { 99.97-99.99\% (in ppm: } \mathrm{Al} 100, \mathrm{Ca} 100, \mathrm{Fe} 50 \\
\text { Si } 20 \text { and Ti } 10 \& \mathrm{Al} 10-100, \mathrm{Ca}<10, \mathrm{Fe} 10 \\
\text { and Ti } 30 \text { ) }\end{array}$ & Routbort [77] \\
\hline & 1948-2008 & $0.62-0.64$ & $\langle 100\rangle$ & $\begin{array}{l}\text { 99.93\% (in ppm. }(\mathrm{Na}+\mathrm{K}) 10, \mathrm{Si} 300, \mathrm{Ca} 330 \text {, } \\
\text { Fe } 70 \text { and }(\mathrm{Ti}+\mathrm{Ni})<10)\end{array}$ & $\begin{array}{l}\text { Ramesh et al. } \\
\text { [78] }\end{array}$ \\
\hline & $1573-1773$ & $0.50-0.57$ & $\langle 100\rangle$ & $\begin{array}{l}\text { 99.962\% (in ppm: } \mathrm{Al} 45, \mathrm{Ca} 280, \mathrm{Cd}<1, \mathrm{Co} 3 \\
\mathrm{Cu} 1, \mathrm{~K} 10, \mathrm{Mn} 22, \mathrm{Mo}<1, \mathrm{Ni} 15, \mathrm{~Pb}<1 \\
\text { and } \mathrm{Zn} 2 \text { ) }\end{array}$ & $\begin{array}{l}\text { Wolfenstine and } \\
\text { Kohlstedt [79] }\end{array}$ \\
\hline \multirow[t]{3}{*}{$\mathrm{NaCl}$} & 1010 & 0.94 & & $\sim 60 \mathrm{ppm}$ of $\mathrm{Ca}^{2+}$ & $\begin{array}{l}\text { Blum and } \\
\text { Ilschner [81] }\end{array}$ \\
\hline & $750-1060$ & $0.7-0.9$ & $\langle 001\rangle$ & $\begin{array}{l}\text { Purest grade Harshaw } \mathrm{NaCl} \text { (impurity } \\
10 \mathrm{ppm} \text { of } \mathrm{Ca}^{2+} \text { ) }\end{array}$ & Poirier [82] \\
\hline & $920-1010$ & $0.85-0.95$ & $\langle 100\rangle$ & Optical quality (impurity < 100 ppm) & $\begin{array}{l}\text { Banerdt and } \\
\text { Sammis [54] }\end{array}$ \\
\hline \multirow[t]{2}{*}{$\begin{array}{l}\text { Dry } \\
\text { Olivine }\end{array}$} & $1701-1923$ & $0.8-0.9$ & & San Carlos $\left(\mathrm{Fo}_{92}\right)$ & $\begin{array}{r}\text { Kohlstedt and } \\
\text { Goetze [52] }\end{array}$ \\
\hline & 1843 & 0.86 & & San Carlos $\left(\mathrm{FO}_{92}\right)$ & Justice et al. [53] \\
\hline Forsterite & $1673-1923$ & $0.78-0.90$ & {$[110]_{\mathrm{c}},[101]_{\mathrm{c}},[011]_{\mathrm{c}}$} & $\mathrm{Fo}_{100}$ & $\begin{array}{l}\text { Darot and } \\
\quad \text { Gueguen [85] }\end{array}$ \\
\hline
\end{tabular}

Table 2 Creep of polycrystals

\begin{tabular}{|c|c|c|c|c|c|}
\hline Material & $\begin{array}{l}\text { Temperature } \\
(\mathrm{K})\end{array}$ & $\begin{array}{l}\text { Homologous } \\
\text { Temperature }\end{array}$ & $\begin{array}{l}\text { Grain Size } \\
(\mu \mathrm{m})\end{array}$ & Purity/Impurity & Reference \\
\hline $\mathrm{CaO}$ & 1473 & 0.52 & 20 & $\begin{array}{l}98.86 \% \mathrm{CaO}, 0.53 \% \mathrm{SiO}_{2}, 0.50 \% \\
\mathrm{Al}_{2} \mathrm{O}_{3}, 0.04 \% \mathrm{Fe}_{2} \mathrm{O}_{3} \text { and } 0.07 \% \\
\text { other oxides }\end{array}$ & $\begin{array}{l}\text { Dixon-Stubbs and } \\
\text { Wilshire [55] }\end{array}$ \\
\hline $\mathrm{LiF}$ & $673-823$ & $0.59-0.72$ & 160 and 3000 & Divalent impurity $<20 \mathrm{ppm}$ & $\begin{array}{l}\text { Cropper and Langdon } \\
\text { [67] }\end{array}$ \\
\hline \multirow[t]{2}{*}{$\mathrm{MgO}$} & $1573-1773$ & $0.50-0.57$ & $13-68$ & & Hensler and Cullen [73] \\
\hline & 1473 & 0.47 & $12-62$ & $\begin{array}{l}\text { 99.98\% (Impurities: } \mathrm{Fe}<20, \mathrm{Si}: 30, \\
\text { Al: } 10, \mathrm{Cu}: 5, \mathrm{Ni}<10, \mathrm{Sr}<50, \mathrm{Ca}: 40 \\
\text { and } \mathrm{Li}: 75)\end{array}$ & Langdon and Pask [74] \\
\hline $\mathrm{NaCl}$ & 638-1015 & $0.60-0.95$ & $200-300$ & & Burke $[80]$ \\
\hline $\begin{array}{l}\text { Dry } \\
\text { Olivine }\end{array}$ & $1253-1873$ & $0.59-0.88$ & $25-2000$ & & Schwenn and Goetze [83] \\
\hline Forsterite & $1718-1873$ & $0.80-0.88$ & $\begin{array}{l}60,98 \text { and } \\
132\end{array}$ & $\mathrm{Fo}_{100}$ & Relandeau [84] \\
\hline
\end{tabular}


Table 3 Values for $D$ and $G$

\begin{tabular}{|c|c|c|c|c|c|c|c|}
\hline Material & Active ion & $D_{0}\left(\mathrm{~m}^{2} \mathrm{~s}^{-1}\right)$ & $\mathrm{Q}\left(\mathrm{kJ} \mathrm{mol}^{-1}\right)$ & References & $G_{\mathrm{o}}(\mathrm{MPa})$ & $\Delta G\left(\mathrm{MPa} \mathrm{K}^{-1}\right)$ & References \\
\hline $\mathrm{CaO}$ & $\mathrm{O}^{2-}$ & $2.0 \times 10^{-10}$ & 345 & [66] & 91.46 & 0.021 & [86] \\
\hline $\mathrm{LiF}$ & $\mathrm{F}^{-}$ & $6.4 \times 10^{-3}$ & 214 & [87] & $5.52 \times 10^{4}$ & 33.2 & [88] \\
\hline $\mathrm{MgO}$ & $\mathrm{O}^{2-}$ & $2.5 \times 10^{-10}$ & 261 & [89] & $1.39 \times 10^{5}$ & 26.2 & [90] \\
\hline $\mathrm{NaCl}$ & $\mathrm{Cl}^{-}$ & $1.2 \times 10^{-2}$ & 214 & [91] & $1.79 \times 10^{4}$ & 9.6 & [88] \\
\hline Olivine & $\mathrm{Si}^{4+}$ & $1.5 \times 10^{-10}$ & 376 & {$[92]$} & $8.49 \times 10^{4}$ & 13.30 & [92] \\
\hline Forsterite & $\mathrm{Si}^{4+}$ & $1.5 \times 10^{-10}$ & 376 & & $8.49 \times 10^{4}$ & 13.30 & \\
\hline
\end{tabular}

very high purity and with a low initial dislocation density tested at very low stresses to reasonably high strains at very high homologous temperatures (at or above $\sim 0.95 T_{\mathrm{m}}$ ). In addition, and as documented in an earlier report [65], there are three specific requirements that must be fulfilled in order to establish the occurrence of Harper-Dorn creep:

(1) Harper-Dorn creep is traditionally regarded as a Newtonian viscous process with $n=1$. Some very recent experimental evidence suggests that the stress exponent may be closer to $\sim 2[34,37,40]$ but nevertheless it is important to uniquely establish a low-stress creep regime where the stress exponent is lower than in the conventional power-law regime where $n \approx 3-5$.

(2) Unlike Nabarro-Herring diffusion creep where there is a dependence on grain size because $p=2$, the Harper-Dorn flow process is independent of grain size and $p=0$. Therefore, it is important to show that, as in the initial experiments of Harper and Dorn [10], identical creep rates are recorded either over a wide range of grain sizes in polycrystalline samples or in a combination of polycrystalline samples and single crystals.

(3) As also demonstrated by Harper and Dorn [10], it is important to confirm by calculation that the measured creep rates are significantly faster, typically by more than two orders of magnitude, than the creep rates anticipated for NabarroHerring diffusion creep. In view of the very high testing temperatures, Coble diffusion creep will be of negligible significance under these conditions.

There is also an additional experimental procedure that was proposed in order to unambiguously distinguish between Harper-Dorn creep and Nabarro-Herring diffusion creep $[94,95]$. When materials deform by diffusion creep, either through Nabarro-Herring creep or Coble creep, the grain become elongated along the tensile axis and accordingly they become displaced with respect to each other thereby creating offsets in marker lines where they impinge on the grain boundaries in the process known as Lifshitz grain boundary sliding [96]. This process is mechanistically different from Rachinger grain boundary sliding which occurs, as in conventional superplasticity [97], when the grains of a polycrystal move over each other in direct response to an external stress. By contrast, Harper-Dorn creep appears to take place through an intragranular dislocation process, the measured strain rate is independent of the grain size, there is no mass flow of vacancies and accordingly no offsets are produced in any surface markers.

It is instructive to note that, as documented elsewhere $[98,99]$, an absence of offsets in surface marker lines was first documented in the very early and careful experiments of Harper et al. [12] where measurements were taken to determine the contribution of grain boundary sliding to the total strain within the region of Harper-Dorn creep. Their early result is shown in Fig. 8 where the percentage contribution from grain boundary sliding, $\xi$, is plotted against the applied stress for pure aluminum tested at $920 \mathrm{~K}$ with a grain size of $3.25 \mathrm{~mm}$. In this plot, dislocation creep with $n=4.5$ occurs at the higher stresses on the right, Harper-Dorn creep with $n=1$ occurs at the lower stresses on the left and the datum points clearly increase initially with decreasing stress towards the transition stress at

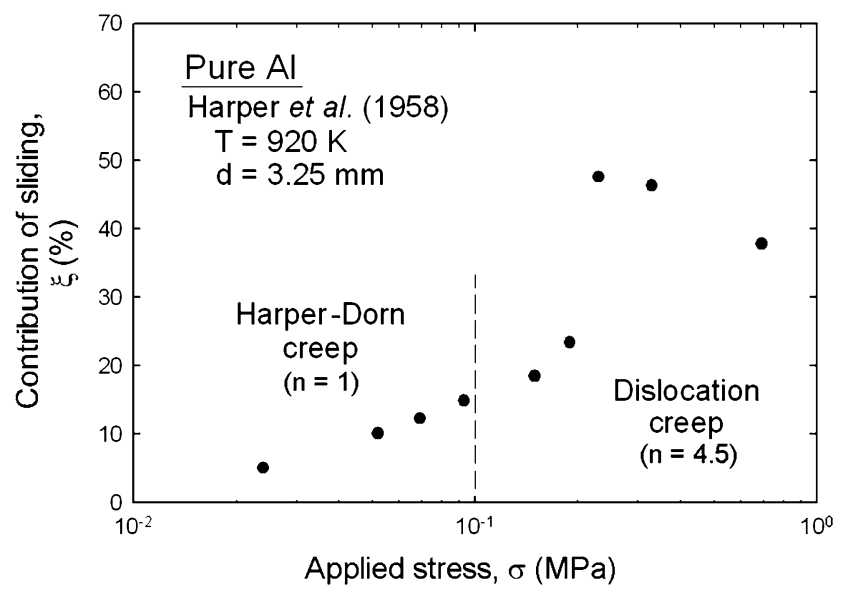

Fig. 8 Contribution of grain boundary sliding to the total strain versus the applied stress for tests on pure aluminum at $923 \mathrm{~K}$ [12] 
0.1 MPa but at the lowest stresses, within the HarperDorn region when $\sigma<0.1 \mathrm{MPa}$, the values recorded for $\xi$ lie within the range of $\sim 5-15 \%$. These very low values of $\xi$ demonstrate conclusively that HarperDorn creep is a unique and different flow mechanism from conventional Nabarro-Herring diffusion creep because the values recorded for $\xi$ in diffusion creep are consistently high and invariably close to $\sim 60 \%$ [100102]. Thus, based on the preponderance of experimental evidence available to date, accumulated over a period of 50 years, it is incontrovertible that HarperDorn creep must be recognized as a unique and different creep mechanism. Clearly, more experiments with marker lines, of the type shown in Fig. 8, are now urgently needed to better substantiate the precise characteristics of the deformation process occurring at these very low stress levels.

\section{Summary and conclusions}

1. Early experiments by Harper and Dorn, conducted on pure aluminum at a very high homologous temperature, suggested the advent of a new and unique creep mechanism at low applied stresses. Specifically, there was evidence for a flow process having a stress exponent of $n=1$, an activation energy for lattice self-diffusion and no dependence on grain size so that the same creep rates were recorded for polycrystalline materials and single crystals. Furthermore, the measured creep rates were faster by a factor of approximately $\sim 1400$ than the rates predicted for Nabarro-Herring diffusion creep.

2. Subsequent experiments have partially supported and partially negated the occurrence of HarperDorn creep as a distinct flow process. The most recent results show that the occurrence of HarperDorn creep requires a material having both a very high purity and a low initial dislocation density. There is also some recent evidence suggesting that, if the samples are tested to sufficiently high strains, the stress exponent may be closer to $\sim 2$.

3. Although the preponderance of experimental evidence supports the occurrence of Harper-Dorn creep as a distinct mechanism under at least some conditions, nevertheless more definitive experiments are needed both to more fully establish the precise requirements for observing this process and to provide detailed information that may be used to develop an appropriate theoretical flow mechanism.
4. The early experiments by Dorn and co-workers established, through measurements with surface marker lines, that grain boundary sliding made no significant contribution to the overall strain in Harper-Dorn creep. This observation clearly demonstrates the absence of diffusion creep but, surprisingly, no additional measurements of this type have been undertaken. It is suggested that careful long-term creep tests, combined with measurements of surface marker lines, would provide useful information in fully establishing the viability of the Harper-Dorn creep process.

Acknowledgements This work was supported in part by the National Science Foundation of the United States under Grant No. DMR-0243331.

\section{References}

1. Bird JE, Mukherjee AK, Dorn JE (1969) In: Brandon DG, Rosen A (eds) Quantitative relation between properties and microstructure. Israel Universities Press, Jerusalem, Israel, p 255

2. Kassner ME, Pérez-Prado M-T (2000) Prog Mater Sci 45:1

3. Cannon WR, Langdon TG (1983) J Mater Sci 18:1

4. Cannon WR, Langdon TG (1988) J Mater Sci 23:1

5. Poirier J-P (1985) Creep of crystals. Cambridge University Press, Cambridge, U.K

6. Langdon TG (1973) In: Whalley E, Jones SJ, Gold LW (eds) Physics and chemistry of ice. Royal Society of Canada, Ottawa, Canada, p 356

7. Nabarro FRN (1948) Report of a conference on strength of solids, The Physical Society, London, U.K., p 75

8. Herring C (1950) J Appl Phys 21:437

9. Coble RL (1963) J Appl Phys 34:1679

10. Harper J, Dorn JE (1957) Acta Metall 5:654

11. Greenwood GW (1999) In: Mishra RS, Mukherjee AK, Murty KL (eds) Creep behavior of advanced materials for the 21st century. The Minerals, Metals and Materials Society, Warrendale, PA, p 413

12. Harper JG, Shepard LA, Dorn JE (1958) Acta Metall 4:509

13. Weertman J (1978) Phil Trans Roy Soc London A 288:9

14. Langdon TG, Dehghan A, Sammis CG (1982) In: Gifkins RC (ed) Strength of metals and alloys (ICSMA 6). Pergamon Press, Oxford, U.K., vol. 2, p 757

15. Van Orman JA (2004) Geophys Res Lett 31:L20606

16. Poirier J-P, Peyronneau J, Gesland JY, Brebec G (1983) Phys Earth Planet Interiors 32:273

17. Beauchesne S, Poirier J-P (1990) Phys Earth Planet Interiors 61:182

18. Weertman J, Blacic J (1984) Geophys Res lett 11:117

19. Blum W, Maier W (1999) Phys Stat Sol (a) 171:467

20. Evans AG, Langdon TG (1976) Prog Mater Sci 21:171

21. Nabarro FRN (2000) Phys Stat Sol (a) 182:627

22. Ruano OA, Wadsworth J, Wolfenstine J, Sherby OD (1993) Mater Sci Eng A165:133

23. Barrett CR, Muehleisen EC, Nix WD (1972) Mater Sci Eng 10:33

24. Muehleisen EC, Barrett CR, Nix WD (1970) Scripta Metall 4:995 
25. Burton B (1972) Phil Mag 25:645

26. Murty KL, Mohamed FA, Dorn JE (1972) Acta Metall 20:1009

27. Mohamed FA, Murty KL, Morris JW (1973) Metall Trans 4:935

28. Murty KL (1974) Mater Sci Eng 14:169

29. Mohamed FA (1978) Metall Trans 9A:1343

30. Yavari P, Mohamed FA, Langdon TG (1981) Acta Metall 29:1495

31. Yavari P, Miller DA, Langdon TG (1982) Acta Metall 30:871

32. Mohamed FA, Ginter TJ (1982) Acta Metall 30:1869

33. Lee S, Ardell JA (1985) In: McQueen HJ, Baïlon J-P, Dickson JI, Jonas JJ, Akben MG (eds) Strength of metals and alloys (ICSMA 7). Pergamon Press, Oxford, U.K., vol. $1, \mathrm{p} 671$

34. Ginter TJ, Chaudhury PK, Mohamed FA (2001) Acta Mater 49:263

35. Ginter TJ, Mohamed FA (2002) Mater Sci Eng A322:148

36. McNee KR, Jones H, Greenwood GW (2001) In Parker JD (ed) Creep and fracture of engineering materials and structures. The Institute of Materials, London, U.K., p 185

37. Srivastava V, McNee KR, Jones H, Greenwood GW (2005) Mater Sci Tech 21:701

38. Pines BYa, Sirenko AF (1963) Fiz Met Metalloved 15:584

39. Mohamed FA (1979) Mater Sci Eng 40:101

40. Mohamed FA, Mater. Sci. Eng. (in press)

41. Malakondaiah G, Rama Rao P (1979) Scripta Metall 13:1187

42. Malakondaiah G, Rama Rao P (1982) Mater Sci Eng 52:207

43. Malakondaiah G, Rama Rao P (1981) Acta Metall 29:1263

44. Novotný J, Fiala J, Čadek J (1983) Acta Metall 31:1697

45. Fiala J, Novotný J, Čadek J (1983) Mater Sci Eng 60:195

46. Novotný J, Fiala J, Čadek J (1985) Scripta Metall 19:867

47. Novotný J, Fiala J, Čadek J (1985) Acta Metall 33:905

48. Fiala J, Cadek J (1985) Mater Sci Eng 75:117

49. Fiala J, Kloc L, Čadek J (1991) Mater Sci Eng A136:9

50. Kloc L, Fiala J, Čadek J (1995) Mater Sci Eng A202:11

51. Kloc L, Fiala J (2005) Mater Sci Eng A410-411:38

52. Kohlstedt DL, Goetze C (1974) J Geophys Res 79:2045

53. Justice MG, Graham EK, Tressler RE, Tsong IST (1982) Geophys Res Lett 9:1005

54. Banerdt WB, Sammis CG (1985) Phys Earth Planetary Interiors 41:108

55. Dixon-Stubbs PJ, Wilshire B (1982) Phil Mag A 45:519

56. Langdon TG (1983) Phil Mag A 47:L29

57. Wang JN, Hobbs BE, Ord A, Shimamoto T, Toriumi M (1994) Science 265:1204

58. Wang JN (1994) Mater Sci Eng A183:267

59. Wang JN, Toriumi M (1994) Mater Sci Eng A187:97

60. Wang JN (1994) Scripta Metall Mater 30:859
61. Wang JN (1994) Phil Mag Lett 70:81

62. Wang JN, Shimamoto T, Toriumi M (1994) J Mater Sci Lett 13:1451

63. Wang JN (1994) J Am Ceram Soc 77:3036

64. Berbon MZ, Langdon TG (1996) J Mater Sci Lett 15:1664

65. Berbon MZ, Owen DM, Langdon TG (1996) In: Arsenault

RJ, Cole D, Gross T, Sizek H, Liaw P, Parameswaran S,

Kostorz G (eds) The Johannes Weertman Symposium. The

Minerals, Metals and Materials Society, Warrendale, PA, p 145

66. Duong H, Wolfenstine J (1991) J Am Ceram Soc 74:2697

67. Cropper DR, Langdon TG (1968) Phil Mag 18:1181

68. Streb G, Reppich B (1972) Phys Stat Sol A 16:493

69. Cropper DR, Pask JA (1973) Phil Mag 27:1105

70. Ruoff AL, Rao CVSN (1975) J Am Ceram Soc 58:503

71. Yu EC, Li JCM (1977) Phil Mag 36:811

72. Biberger M, Blum W (1989) Scripta Metall 23:1419

73. Hensler JH, Cullen GV (1968) J Am Ceram Soc 51:178

74. Langdon TG, Pask JA (1970) Acta Metall 18:505

75. Cummerow RL (1963) J Appl Phys 34:1724

76. Rothwell WS, Neiman AS (1965) J Appl Phys 36:2309

77. Routbort JL (1979) Acta Metall 27:649

78. Ramesh KS, Yasuda E, Kimura S (1986) J Mater Sci 21:3147

79. Wolfenstine J, Kohlstedt DL (1988) J Mater Sci 23:3550

80. Burke PM (1968) PhD Dissertation, Stanford University, Stanford, CA

81. Blum W, Ilschner B (1967) Phys Stat Sol 20:629

82. Poirier J-P (1972) Phil Mag 26:701

83. Schwenn MB, Goetze C (1978) Tectonophys 48:41

84. Relandeau C (1981) Geophys Res Lett 8:733

85. Darot M, Gueguen Y (1981) J Geophys Res B86:6219

86. Bartels RA, Son PR (1972) J Phys Chem Solids 33:1991

87. Eisenstadt M (1963) Phys Rev 132:630

88. Hart S (1968) J Phys D 1:1285

89. Oishi Y, Kingery WD (1960) J Chem Phys 33:905

90. Soga N, Anderson OL (1966) J Am Ceram Soc 49:355

91. Laurent JF, Benard J (1958) J Phys Chem Solids 7:218

92. Ashby MF, Verrall RA (1978) Phil Trans Roy Soc London 288A:59

93. Houlier B, Cheraghmakani M, Jaoul O (1990) Phys Earth Planetary Interiors 62:329

94. Langdon TG (1996) Scripta Mater 35:733

95. Langdon TG (2000) Mater Sci Eng A283:266

96. Langdon TG (2006) J Mater Sci 41:597

97. Langdon TG (1994) Acta Metall Mater 42:2437

98. Langdon TG (2005) Mater Trans 46:1951

99. Langdon TG (2005) Z Metallkd 96:522

100. Gifkins RC, Langdon TG (1970) Scripta Metall 4:563

101. Crossland IG, Wood JC (1975) Phil Mag 31:1415

102. Kim B-N, Hiraga K (2000) Scripta Mater 42:451 